\title{
Intermittent catheterisation for individuals with disability related to spinal cord injury in Tanzania
}

\author{
Erikael S. Nade ${ }^{1} \cdot$ Marie V. E. Andriessen ${ }^{1} \cdot$ Fabiola Rimoy $^{1} \cdot$ Mihayo Maendeleo $^{1} \cdot$ Vivian Saria $^{1} \cdot$ Haleluya I. Moshi $^{1}$. \\ Marieke C. J. Dekker ${ }^{1}$
}

Received: 1 March 2020 / Revised: 12 July 2020 / Accepted: 13 July 2020

(c) The Author(s), under exclusive licence to International Spinal Cord Society 2020

\begin{abstract}
Study design Cross-sectional pilot study on spinal cord injury (SCI) among in- and outpatients.

Objectives To evaluate the challenges faced by individuals with SCI during Clean Intermittent Catheterisation (CIC).

Setting Kilimanjaro Christian Medical Center (KCMC), a tertiary referral hospital in Moshi, Tanzania.

Methods A questionnaire was sent to individuals with SCI who were either admitted to the Orthopedic Rehabilitation Unit or attended the Outpatient clinic between January and April 2018. Inpatients were less than 1 year post-injury and outpatients were one to 3 years post-injury.

Results In total, 48 individuals responded: 28 outpatients and 20 inpatients. Among the inpatient group, $80 \%$ were performing CIC as compared with $25 \%$ of outpatient group. Of the entire cohort, $35.4 \%$ reported doing well without catheterbased management. Failure to perform CIC was present in $16.7 \%$ of all individuals. CIC-equipment was unavailable in local villages for $58.3 \%$ of all patients. The most frequent complications of CIC were urinary tract infections (20.8\%) and mild bleeding (14.6\%). The majority of individuals (79.2\%) reported satisfaction with their situation, regardless of the severity. Conclusions Some individuals performed CIC upon discharge, but the majority discontinued use, for which unavailability of CIC-equipment was a major determinant. While all individuals reported concerns prior to CIC, only a small minority actually experienced anxiety, pain or shame. Through targeted counselling and enhanced regular follow-up we will likely improve compliance to CIC.

Sponsorship We are grateful to the International Network of SCI Nurses in collaboration with Wellspect Health Care for funding this study.
\end{abstract}

\section{Introduction}

In the United Republic of Tanzania (East Africa), spinal cord injury (SCI) is predominately caused by falling from height and traffic accidents [1,2]. Males are particularly at risk during young adulthood (20-29 years) and older age (70 years and over) and females are most at risk in adolescence (15-19 years) and older age (60 years and over).

These authors contributed equally: Erikael S. Nade, Marie V. E. Andriessen

Marie V. E. Andriessen

m.v.e.andriessen@students.uu.nl

1 Orthopedic Rehabilitation Unit (ORU), KCMC, PO Box 3010, Moshi, Kilimanjaro, Tanzania
Studies report a male to female ratio of $\sim 2: 1$; however, sometimes the ratio is even higher [3]. After SCI, most individuals require catheter-based bladder management due to neurogenic lower urinary tract dysfunction [4]. Indwelling catheters, including both suprapubic and Foley catheters, are associated with more complications than clean intermittent catheterisation (CIC) [4]. Complications of indwelling catheters include urinary tract infection (UTI), bladder and kidney stones, hydronephrosis and renal failure and pressure sores [4].

Therefore, CIC is considered as the golden standard for aided bladder voiding in neurogenic bladder management [4]. Although the benefits of CIC are evident, an American study with a follow-up to 30 years demonstrated that up to $70 \%$ of individuals using CIC switched to an indwelling catheter [5]. Another study by Zlatev et al. found 50\% discontinuation of CIC at 5 years of follow up [6]. On the 
other hand, $66.1 \%$ of Swedish individuals are still performing CIC after up to 30 years of follow-up [7].

The ability to perform CIC is heavily dependent on level and severity of the injury [8]. Feelings of fear and anxiety as well as misconceptions about the risks of CIC can further influence adherence to CIC. To the best of our knowledge, there are no studies from Northern Tanzania regarding CIC in individuals with SCI. This small-scale pilot study aims to fill this geographical gap and identify culture specific as well as global determinants of access to CIC.

\section{Methods}

This is a cross-sectional study with purposive sampling, carried out in Kilimanjaro Christian Medical Center (KCMC), a tertiary referral hospital in Northern Tanzania. The research population consists of individuals with traumatic SCI aged 15-90 years. The population consists of inpatients admitted to the Spinal Cord Unit of KCMC and outpatients visiting the orthopaedic outpatient clinic at KCMC in the period from January to April 2018. Inpatients were all less than a year post injury, while all outpatients had their injury between 1 year and 3 years ago at the time of examination. Routine follow-up of individuals with SCI only started after the foundation of the SCI unit in KCMC, which explains the maximum follow-up of 3 years. Discharged individuals were seen in the outpatient clinic, or were visited in their homes.

Individuals with SCI who were using indwelling catheters for various reasons (early stage of admission, surgical or pre-existent comorbidity with inability to sit or injury of the hands due to other, non-spinal injury related reasons), were excluded from this study. Written (or written by proxy) informed consent was required beforehand. Successful intermittent catheterisation was defined as catheterisation carried out by the individual or by their relative. The situation was defined as failure to catheterisation when there were complications or material unavailability leading to usage of an indwelling catheter or usage of a condom-style catheter (varying from urological disposable appliances to plastic bags or a disposable non-sterile medical glove).

Independent variables were age, gender, area of residence, income, level of injury, date of admission, ability of the individual with SCI or family member to perform CIC, perception towards intermittent catheterisation, mechanism of injury, duration of SCI, type of injury, method used to retrain the bladder and type of caregiver performing intermittent catheterisation. Completeness of the injury was defined as complete (AIS A) or incomplete (AIS B, C or D). Dependent variables were challenges and complications during the use of CIC, measures taken to resolve the complications and presence of promotion of CIC among
Table 1 Socio-demographic characteristics of individuals with traumatic SCI $(n=48)$.

\begin{tabular}{lc}
\hline Characteristics & Frequency (percentage) \\
\hline Sex & \\
Male & $45(93.8 \%)$ \\
Female & $3(6.2 \%)$ \\
Age group & \\
15-25 & $4(8.3 \%)$ \\
$26-35$ & $16(33.3 \%)$ \\
$36-45$ & $14(29.2 \%)$ \\
$46-60$ & $14(29.2 \%)$ \\
Economic status & \\
Poor & $16(33.3 \%)$ \\
Moderate & $30(62.5 \%)$ \\
High & $2(4.2 \%)$ \\
Type of accident & \\
Motorbike accident & $17(35.4 \%)$ \\
Car accident & $8(16.7 \%)$ \\
Fall from height & $23(47.9 \%)$ \\
Level of injury & \\
Cervical & $17(35.4 \%)$ \\
Thoracic & $28(58.3 \%)$ \\
Lumbar & $2(4.3 \%)$ \\
Severity of injury & \\
Incomplete injury & $6(87.5 \%)$ \\
Complete injury & \\
\hline & \\
\hline &
\end{tabular}

individuals with SCI. Levels of satisfaction and obstacles encountered were requested on a scale from 0 to 10 points, where 0 to 5 points were rated as negative and 6 to 10 points as positive. Individuals were asked to arrange their concerns according to the importance they gave to it, and the greatest concern with respect to medical or nursing care was documented. The questionnaire was written in English, translated to Swahili, and then translated back to English. Audio tape was used for those individuals who agreed to be taped during the interview.

\section{Results}

A total of 66 individuals were asked to participate from January to April 2018, of whom 48 agreed. Characteristics of the participants are summarized in Table 1 . The most common causes of SCI included falling from height (23/48; $47.9 \%)$, motorbike accident $(17 / 48 ; 35.4 \%)$ and car accident $(8 / 48 ; 16.7 \%)$.

In this cohort, $23 / 48$ individuals $(47.9 \%)$ were successfully performing CIC at the time of the questionnaire, with or without help of relatives (Table 2). Stratification for inand outpatients demonstrated $80 \%$ of inpatients and $25 \%$ of 
Table 2 Challenges faced by individuals with SCI overall ( $n$ $=48$ ), and the attribution of inand outpatients.

\begin{tabular}{|c|c|c|c|}
\hline Challenges & $\begin{array}{l}\text { Total } \\
\text { (percentage) }\end{array}$ & $\begin{array}{l}\text { Number inpatients } \\
\text { (percentage inpatients) }^{\mathrm{a}}\end{array}$ & $\begin{array}{l}\text { Number outpatients } \\
\text { (percentage outpatients) }^{\mathrm{b}}\end{array}$ \\
\hline \multicolumn{4}{|c|}{ Ability of individual/peer to perform CIC } \\
\hline Total performing CIC & $23(47.9 \%)$ & $16(80 \%)$ & $7(25 \%)$ \\
\hline - Individual performs CIC & $8(16.7 \%)$ & $6(30 \%)$ & $2(7.1 \%)$ \\
\hline $\begin{array}{l}\text { - Family member } \\
\text { performs CIC }\end{array}$ & $15(31.3 \%)$ & $10(50 \%)$ & $5(17.9 \%)$ \\
\hline Unable to perform CIC & $8(16.7 \%)$ & $2(10 \%)$ & $6(21.4 \%)$ \\
\hline No need of CIC reported & $17(35.4 \%)$ & $2(10 \%)$ & $15(53.6 \%)$ \\
\hline \multicolumn{4}{|l|}{ Availability of CIC equipment } \\
\hline Available at home & $9(18.8 \%)$ & 0 & $9(32.1 \%)$ \\
\hline $\begin{array}{l}\text { Insufficiently available at } \\
\text { home }\end{array}$ & $28(58.3 \%)$ & $10(50 \%)$ & $18(64.2 \%)$ \\
\hline $\begin{array}{l}\text { Availability at home } \\
\text { unknown }\end{array}$ & $9(18.8 \%)$ & $9(45 \%)$ & 0 \\
\hline Not necessary & $2(4.2 \%)$ & $1(5 \%)$ & $1(3.6 \%)$ \\
\hline \multicolumn{4}{|l|}{ Obstacle for CIC } \\
\hline Insufficient hand function & $14(29.2 \%)$ & $8(40 \%)$ & $6(21.4 \%)$ \\
\hline Unable to sit properly & $15(31.3 \%)$ & $10(50 \%)$ & $5(17.9 \%)$ \\
\hline Spasticity & $7(14.6 \%)$ & $2(10 \%)$ & $5(17.9 \%)$ \\
\hline No obstacle encountered & $12(25 \%)$ & 0 & $12(42.9 \%)^{\mathrm{c}}$ \\
\hline \multicolumn{4}{|c|}{ Greatest concern prior to starting CIC } \\
\hline Pain & $10(20.8 \%)$ & $4(20 \%)$ & $6(21.4 \%)$ \\
\hline Shame & $11(22.9 \%)$ & $4(20 \%)$ & $7(25 \%)$ \\
\hline Infections & $2(4.2 \%)$ & $1(5 \%)$ & $1(3.6 \%)$ \\
\hline Bleeding & $6(12.5 \%)$ & $2(10 \%)$ & $4(14.3 \%)$ \\
\hline Unable to urinate again & $13(27.1 \%)$ & $8(40 \%)$ & $5(17.9 \%)$ \\
\hline $\begin{array}{l}\text { Damage to genitals, urethra } \\
\text { and bladder }\end{array}$ & $6(12.5 \%)$ & $1(5 \%)$ & $5(17.9 \%)$ \\
\hline \multicolumn{4}{|c|}{ Individual's satisfaction about present situation } \\
\hline Satisfied & $38(79.2 \%)$ & $13(65 \%)$ & $25(89.3 \%)$ \\
\hline Not satisfied & $10(20.8 \%)$ & $7(35 \%)$ & $3(10.7 \%)$ \\
\hline
\end{tabular}

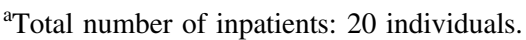

${ }^{\mathrm{b}}$ Total number of outpatients: 28 individuals.

${ }^{\mathrm{c}}$ Some of outpatients reporting no obstacles are not conducting CIC at the moment of the questionnaire. outpatients performing CIC. Eight individuals (16.7\% of the total group) performed CIC independently, including the three females in the study population. Seventeen individuals reported doing well without CIC (35.4\%); these individuals included spontaneous voiders and individuals managing with bladder percussion. However, information about residual bladder volumes was absent. The outpatients, 28 individuals all over 1 year post-SCI, were less likely to perform CIC. Eight individuals of the total group (16.7\%) (6 outpatients and 2 inpatients) failed to use any means of $\mathrm{CIC}$ at the time of the questionnaire due to urethral stricture, pressure sores believed related to urine leakage or unavailability of catheters.

A major obstacle for the implementation and continuation of CIC in individuals with SCI in Northern Tanzania is the availability of CIC equipment for home-usage. Most individuals (58.3\%) do not have access to CIC equipment in their local villages. Other obstacles to perform CIC include inability to sit (31.3\%), insufficient hand function (29.2\%) and spasticity (14.6\%) (Table 2).

Before starting with intermittent self-catheterisation most individuals had concerns such as fear of pain, fear of infections, fear of bleeding, fear of inflicting harm to the genitals, fear of being unable to urinate again and shame (Table 2). The most prominent complications during CIC (Table 3) were UTIs (9 individuals, $39.2 \%$ of all patients performing CIC) and mild bleeding on the first few days of CIC (7 individuals; $30.5 \%$ of all inpatients). In the 7 outpatients on CIC, catheter leakage and urethral stricture were also mentioned as complications. Most individuals with a 
Table 3 The main complication as reported by individuals conducting CIC overall ( $n=23)$, and with specification of in- and outpatient attribution.

Complications of CIC Total having the complication (percentage)

\begin{tabular}{ll}
\hline UTI with fever & $9(39.2 \%)$ \\
Urethral bleeding upon initiation of CIC & $7(30.5 \%)$ \\
Pain during CIC & $1(4.3 \%)$ \\
Urine leakage causing pressure sores & $1(4.3 \%)$ \\
Urethral stricture & $1(4.3 \%)$ \\
No complication & $4(17.4 \%)$
\end{tabular}

Number inpatients (percentage of inpatients $)^{\mathrm{a}}$

$\begin{array}{lc}4(25 \%) & 5(71 \%) \\ 7(44 \%) & 0 \\ 1(6 \%) & 0 \\ 0 & 1(14.5 \%) \\ 0 & 1(14.5 \%) \\ 4(25 \%) & 0\end{array}$

CIC clean intermittent catheterisation, UTI urinary tract infection.

${ }^{a}$ Total number of inpatients conducting CIC: 16 individuals.

${ }^{\mathrm{b}}$ Total number of outpatients conducting CIC: 7 individuals.

UTI confirmed by urine analysis were treated with ciprofloxacin 500 milligrams (mg) twice a day for 5 to 7 days. Urine analysis was only performed in patients with fever who were suspected of UTI. No urine cultures were performed due to unavailability of the test and/or the financial situation of the individuals. When there was anxiety, shame or pain during catheterisation, individuals were counselled by medical staff. Mild bleeding during the first days of catheterisation usually resolved without treatment.

\section{Discussion}

Tanzania has a population of $\sim 53$ million individuals, of which over $70 \%$ are younger than 30 years old. Tanzania's per capita income is ranked 186th worldwide [9]. This lack of financial means is the single most important complicating factor for the average Tanzanian who incurs a disability. The study includes 48 individuals with SCI, of whom the majority were male, similar to other countries around the world. Most individuals with SCI in Tanzania are subsistence farmers (65\% of our patients; data not shown) who climb trees to harvest crops or collect food for their cattle. Consequently, the most common trauma mechanism is falling from height, which reflects an only partially industrialised society in which nationals need to gather food from perilous locations, similar to other developing countries $[1,10]$.

Sixteen out of 20 inpatients were using CIC upon discharge $(80 \%)$, which is compatible with or even slightly higher than the percentage found in other studies $[5,6,11,12]$. However, in the outpatient population, CIC usage had fallen to $25 \%$ of all respondents. Percentages in other studies are diverse, ranging from 36 to $66 \%$ $[7,11,12]$. The relatively low percentage in this study can partially be explained by the large percentage of individuals with tetraplegia in this cohort, who are known to discontinue CIC more often $[6,12]$. In our cohort $35.4 \%$ of the individuals had a cervical lesion, while in other studies only $14-28 \%$ of subjects had tetraplegia $[7,11,12]$. However, the main reason to discontinue CIC in our setting is most likely the unavailability and unaffordability of materials and personnel.

In rural Northern Tanzania there is no easy access to CIC supplies. CIC supplies are scarce and only a minority of Tanzanians are insured for healthcare expenses. The healthcare insurance rate in Tanzania overall is lower than $5 \%$ according to a WHO survey in 2015 [13], although efforts are being made to increase coverage nationwide. Individuals with SCI are mostly from a relatively poor segment of the total population, such as subsistence farmers, with an even lower healthcare insurance rate. This implies that an acute and permanent injury such as SCI will cause prohibitive and lifelong expenses for almost all individuals in this study. Only one individual in this study, whose income was rated above low socioeconomic status (data not shown), had healthcare insurance.

Seventeen individuals in this cohort $(35.4 \%)$ reported doing well without CIC, including 2 inpatients (10\%) and 15 outpatients $(53.6 \%)$. This group includes spontaneous voiders and individuals using bladder percussion. Other studies demonstrated 20-27\% of the individuals with SCI's performing normal voiding and/or reflex voiding at discharge $[5,6,11]$. Cameron et al. found this percentage to be stable in 0-30 years of follow-up, while Afsar et al. found $49 \%$ of the individuals doing well without CIC after a mean follow-up of 53.9 months $[5,11]$.

Our study has a high percentage of outpatients selfreporting to do well without CIC. An important explanation could be that our cohort does not have information on residual bladder volumes or on urodynamic results because of unavailability of bladder scanning or urodynamic studies. Elsewhere, persistent residual bladder volumes and elevated bladder pressure is an indication for catheter-based management. However, residual volumes remain undetected in this cohort, because there are no measuring techniques 
available. Catheterisation after spontaneous voiding is not routinely instructed and hampered by the difficulty in obtaining catheters. We therefore believe that some of the individuals reporting normal voiding or conducting bladder percussion, are at risk of long-term complications and would be better off on CIC.

All three females in this cohort learned to perform CIC and continued CIC. Although the sample size is small, this is a remarkable detail given the fact that most other studies demonstrated that female sex is a risk factor for indwelling catheter usage [5, 6, 12], and discontinuation of catheter usage [5].

The biggest concern of individuals prior to starting CIC was fear of being unable to urinate again, followed by embarrassment and fear of pain. Inpatients have "fear of being unable to urinate again" as their biggest concern, while outpatients are relatively more affected by embarrassment. Interestingly, only a small minority of the individuals reported pain, anxiety or shame during CIC. This illustrates the importance of counselling individuals, because anticipatory anxiety appears to be much greater than during the performance.

Out of all 48 respondents, the majority (79.2\%) reported they were satisfied with their situation, whether conducting CIC, having an indwelling catheter, using a condom catheter, or voiding normally. Satisfaction was observed across all groups, but outpatients appear to be more satisfied than inpatients $(89.3 \%$ versus $65 \%)$. This has probably to do with the fact that inpatients are still processing the major life event that SCI entails. Uncomplicated CIC was hardly seen in our cohort. All outpatients conducting CIC reported complications and only 4 of the inpatients (20\%) reported no complications (Table 3).

Our study has multiple limitations. The small sample size makes the study a feasibility or pilot study. We hope to repeat this study with a larger number of subjects over a larger period of time and with more systematic methods, such as standard assessment of injury according to international scoring systems; for instance the 2019 International Standards for Neurological Classification of Spinal Cord Injury or the International Standards to document remaining Autonomic Function after Spinal Cord Injury $[14,15]$. Associated autonomic and urological performance scores will add to the generalisability of these clinical assessments.

This study was performed in a nascent stage of the dedicated KCMC SCI unit which is now operational. Thus, systematic workup was not possible yet. Another limitation is the relatively short period of follow-up of individuals with SCI, which is up to three years after the injury. Followup of these individuals only started after the foundation of the SCI unit in KCMC, 3 years ago. On the other hand, this is the only dedicated SCI unit in Tanzania and will remain an optimal sampling site for this condition. Another limitation is the relatively low response rate on the submitted questionnaires $(72.7 \%)$. This might result in selection bias, causing an underestimation of the severity of the individual's problems. Moreover, some of the most severely affected non-responders may have already passed away, or might have decided to live with other family members to receive adequate care. This often requires a change of address and they may not have received the survey questionnaire. Finally, it is conceivable that satisfied individuals are more inclined to reply to a survey than dissatisfied individuals.

Even though our small sample size does not allow for definitive conclusions, our study demonstrates that CIC management is possible in Sub-Saharan Africa. The circumstances are challenging, and our results may underestimate the rate of complications due to a lack of professional follow up. Nevertheless, there is potential benefit from improved outpatient follow-up and availability of CIC equipment. Raising awareness for these vulnerable individuals is of utmost importance in order to establish safer and more adequate bladder voiding conditions.

Acknowledgements First, we want to express our appreciation to all participating individuals with SCI and their families. This study was supported through the International Network of Spinal Cord Injury Nursing in collaboration with Wellspect Health Care.

\section{Compliance with ethical standards}

Conflict of interest The authors declare that they have no conflict of interest.

Publisher's note Springer Nature remains neutral with regard to jurisdictional claims in published maps and institutional affiliations.

\section{References}

1. Rashid SM, Jusabani MA, Mandari FN, Dekker MCJ. The characteristics of traumatic spinal cord injuries at a referral hospital in Northern Tanzania. Spinal Cord Ser Cases. 2017;3:2-5. https:// doi.org/10.1038/scsandc.2017.21.

2. Moshi H, Sundelin G, Sahlen KG, Sörlin A Traumatic spinal cord injury in the north-east Tanzania - describing incidence, etiology and clinical outcomes retrospectively. Glob Health Action. 2017;10. https://doi.org/10.1080/16549716.2017.1355604.

3. WHO. International perspectives on spinal cord injury (IPSCI). Top Spinal Cord Inj Rehabil [Internet]. 2011;16:99-100. http:// ovidsp.ovid.com/ovidweb.cgi? $=\mathrm{JS} \& \mathrm{PAGE}=$ reference $\& \mathrm{D}=$ emed10\&NEWS $=$ N\&AN $=70724512$.

4. Patel DP, Herrick JS, Stoffel JT, Elliott SP, Lenherr SM, Presson $\mathrm{AP}$, et al. Reasons for cessation of clean intermittent catheterization after spinal cord injury: results from the Neurogenic Bladder Research Group spinal cord injury registry. Neurourol Urodyn. 2020;39:211-9. https://doi.org/10.1002/nau.24172.

5. Cameron AP, Wallner LP, Tate DG, Sarma AV, Rodriguez GM, Clemens JQ. Bladder management after spinal cord injury in the 
United States 1972 to 2005. J Urol. 2010;184:213-7. https://doi. org/10.1016/j.juro.2010.03.008.

6. Zlatev DV, Shem K, Elliott CS. Predictors of long-term bladder management in spinal cord injury patients-Upper extremity function may matter most. Neurourol Urodyn. 2018;37:1106-12.

7. Hagen EM, Rekand T. Management of bladder dysfunction and satisfaction of life after spinal cord injury in Norway. J Spinal Cord Med. 2014;37:310-6.

8. Zlatev DV, Shem K, Elliott CS. How many spinal cord injury patients can catheterize their own bladder? The epidemiology of upper extremity function as it affects bladder management. Spinal Cord. 2016;54:287-91.

9. Gapminder. Gapminder [Internet]. [cited 2020 May 5]. https://www.gapminder.org/.

10. Chiu WT, Lin HC, Lam C, Chu SF, Chiang YH, Tsai SH. Epidemiology of traumatic spinal cord injury: Comparisons between developed and developing countries. Asia-Pac J Public Health. 2010;22:9-18.
11. Afsar SI, Yemisci OU, Cosar SNS, Cetin N. Compliance with clean intermittent catheterization in spinal cord injury patients: a long-term follow-up study. Spinal Cord 2013;51:645-9.

12. Yavuzer G, Gök H, Tuncer S, Soygür T, Arikan N, Arasil T. Compliance with bladder management in spinal cord injury patients. Spinal Cord. 2000;38:762-5.

13. World Bank. Gross national income per capita 2018, Atlas method and PPP [Internet]. 2019 [cited 2020 May 5]. pp. 1-4. http://data bank.worldbank.org/data/download/GNIPC.pdf.

14. Krassioukov A, Biering-Sorensen F, Donovan W, Kennelly M, Kirshblum S, Krogh K, et al. International standards to document remaining autonomic function after spinal cord injury (ISAFSCI), first edition 2012. Top Spinal Cord Inj Rehabil. 2012;18:282-96.

15. American Spinal Injury Association A. International Standards for Neurological Classification of SCI (ISNCSCI) [Internet]. 2019 [cited 2020 May 5]. https://asia-spinalinjury.org/international-sta ndards-neurological-classification-sci-isncsci-worksheet/. 